\title{
Influence of specific dietary sugars on the jejunal mechanisms for glucose, galactose, and $\alpha$-methyl glucoside absorption: evidence for multiple sugar carriers
}

\author{
E. S. DEBNAM ${ }^{1}$ AND R. J. LEVIN ${ }^{2}$ \\ From the Department of Physiology, The University of Sheffield, Sheffield
}

SUMmaRY The effects of feeding glucose, galactose, and $\alpha$-methyl glucoside on the kinetics of absorption of these sugars in the jejunum of the fasting rat were assessed by recently developed chemical and electrical methods for characterizing the electrogenic active transfer mechanisms in vivo. The parameters of 'apparent $\mathrm{K}_{\mathrm{m}}$ ' (an index of carrier affinity) and $\mathrm{V}_{\max }$ (an index of the maximum jejunal transfer capacity) were obtained from the kinetic data to describe quantitatively the active transport mechanisms in rats fed their normal solid diet, in rats deprived of solid food for three days, and in rats deprived of solid food but allowed ad libitum access to isotonic solutions of glucose, galactose, or $\alpha$-methyl glucoside for up to three days. Feeding the sugars to fasting rats produced complex differential effects on the 'apparent $\mathrm{K}_{\mathrm{m}}$ 's' and $\mathrm{V}_{\max }$ 's of the various transport mechanisms. The changes, although complex, can best be explained by alterations in the transport mechanisms per se rather than by non-specific changes in intestinal morphology or metabolism. The differential effects induced by the feeding sugars are further evidence for the concept that jejunal enterocytes possess multiple carriers or mechanisms for the absorption of actively transported sugars in vivo. The multiple forms of the sugar carriers (isocarriers?) may be involved in the facultative responses of the enterocytes to changes in the dietary levels of sugar and may be important in understanding the influences of disease and nutritional status on absorption processes in man.

Although the 'level of dietary sugar can influence the intestinal absorption of these nutrients (Westenbrink, 1934; Donhoffer, 1935; Crouzoulon-Bourcat et al., 1971; Roy and Dubois, 1972), the effects of feeding individual sugars on the active transfer mechanisms for specific sugars has never been assessed critically. In order to investigate the influence of specific dietary sugars on the mechanisms for active sugar absorption we fed isotonic solutions of either glucose, galactose, or $\alpha$-methyl glucoside to rats during the whole or part of a three day fast. The absorption by the jejunum of glucose, galactose, or $\alpha$-methyl glucoside was measured kinetically using chemical and electrical techniques that allow the operational kinetic parameters of

1Present address: Department of Physiology, Royal Free Hospital School of Medicine, 8 Hunter Street, London, WC1 1BP.

'Address for correspondence: Dr R. J. Levin, Department of Physiology, University of Sheffield, Sheffield, S10 2TN.

Received for publication 26 November 1975 'apparent $\mathbf{K}_{\mathrm{m}}$ ' and the maximal transfer capacity $\left(V_{\max }\right)$ of the active transfer mechanisms to be obtained in vivo (Debnam and Levin, 1975a, b). The results of these experiments not only reveal the influences of dietary sugars on absorption processes but also give further support for the concept that active sugar absorption is mediated by multiple carrier mechanisms (Debnam and Levin, 1971; 1975b; Levin and Syme, 1971) rather than by a single common carrier (Wilson, 1962).

A preliminary account of the experiments has been published (Debnam and Levin, 1974).

\section{Methods}

\section{ANIMALS AND DIET}

Albino male rats of the Sheffield strain weighing approximately $250 \mathrm{~g}$ were used and were housed individually in wire bottom cages to minimize coprophagy. 
Experiments were performed on rats maintained on Diet 86 (Oxoid Ltd., London) and allowed unlimited access to water. Animals that were fasted had their food removed for three days before the commencement of measuring their absorption but were allowed ad libitum access to water throughout the fast. In the remainder of the animal groups, fasted animals were allowed to drink isotonic glucose $(5.4 \% \mathrm{w} / \mathrm{v})$, galactose $(5.4 \% \mathrm{w} / \mathrm{v})$, or $\alpha$-methyl glucoside $(5.8 \% \mathrm{w} / \mathrm{v})$ dissolved in their drinking water. The rats were allowed access to these sugars either from the whole of the three day fast or for a specific time. In the case of galactose and $\alpha$-methyl glucoside solutions, saccharin had to be added to induce the rats to drink significant quantities for it was found that rats would not freely drink such sugar solutions. In the case of galactose, this is so, despite the fact that it can be metabolized by the liver to provide energy during the fast. Experiments were undertaken to show that saccharin per se, at the concentration used $(17.3 \mathrm{mg} \%)$, did not have an effect upon the kinetic parameters for intestinal sugar absorption. No adverse effect on any of the rats was noted with any of the various dietary sugar regimes. In a few cases slight diarrhoea was observed but this was not restricted to any particular feeding sugar.

In vivo PREPARATION AND MEASUREMENT OF TRANSMURAL POTENTIAL DIFFERENCE

The methods and solutions for circulation through rat mid-jejunum and the recording of the electrical potential differences (pds) generated were identical to those described previously (Debnam and Levin, 1975a). The 'test' sugars circulated through the $20 \mathrm{~cm}$ segment of mid-jejunum to measure absorption were dissolved in bicarbonate saline (Krebs and Henseleit, 1932). The serial concentration rates used for glucose were $4,8,16,32$, and $64 \mathrm{mM}$; for galactose $4,8,16,32,64$, and $128 \mathrm{mM}$, and for $\alpha$-methyl glucoside $4,8,16,32$, and $64 \mathrm{mM}$; all solutions for a particular sugar were made to the same tonicity with mannitol (Debnam and Levin, 1975a).

CHEMICAL AND RADIOACTIVE ESTIMATIONS OF SUGAR ABSORPTION

These were carried out as in the previous study (Debnam and Levin, 1975a). In brief, the sugar absorption measured at each specific concentration by chemical or radioactive estimation was corrected for that amount of sugar absorbed by the 'diffusive, non-electrogenic' pathway-that is, that obtained in the presence of $5 \times 10^{4} \mathrm{M}$ phlorridzin. Thus a series of 'diffusion-corrected' values representing active electrogenic absorption were obtained for each sugar concentration in the various dietary conditions.

ESTIMATION OF OPERATIONAL KINETIC PARAMETERS FROM ELECTRICAL AND CHEMICAL ABSORPTION DATA

The plot of Lineweaver and Burk (1934) was used to obtain the operational kinetic parameters of 'apparent $\mathrm{K}_{\mathrm{m}}$ ' (mM) and $\mathrm{V}_{\max }$ (maximum absorptive capacity expressed as $\mu \mathrm{mol} / 10 \mathrm{~cm}$ mid-jejunum $15 \mathrm{~min}$ ) from the corrected chemical absorption data. In the time course studies, the sugars were fed to fasting rats to see how quickly the transport mechanisms were affected and the 'apparent $K_{m}$ 's' were obtained from the transfer pds. The $\mathrm{pd}_{\max }$ (maximum pd developed by the electrogenic mechanism) has not been used due to the marked lack of correspondence with the $V_{\max }$ observed in previous in vivo studies (Debnam and Levin, 1975a, b). The significance of the differences between the various operational parameters of electrogenic hexose transport was assessed by the unpaired $t$ test.

INTESTINAL WEIGHT MEASUREMENTS

On completion of the circulation procedure with the sugar solutions (approximately 2.5-3 h), the cannulated gut segment was removed from the intestine and excess fluid allowed to drain away. The segment was then blotted dry on filter paper (Whatman No. 50) and its length measured by laying on damp blotting paper so that it was just extended without applying any excess tension. The dry weight was determined by drying the segment to a constant weight at $100^{\circ} \mathrm{C}$.

\section{CHEMICALS}

Glucose was obtained from May \& Baker Ltd., galactose (for feeding purposes) and $a$-methyl glucoside from BDH Ltd., and galactose (as the 'test' sugar) from Mann Research Labs. $\mathrm{C}^{14}-\alpha-$ methyl glucoside was purchased from The Radiochemical Centre and phlorridzin from Phase Separation Ltd., Flintshire. Saccharin was purchased from Boots Ltd. in tablet form.

\section{Results}

EFFECT OF DIETARY SUGAR ON INTESTINAL WEIGHT

The results obtained for the dry weights of a $10 \mathrm{~cm}$ section of mid-jejunum from fed rats and rats fasted for three days together with those fasted for three days and fed the various dietary sugars are shown in Table 1. Significant increases in the intestinal dry weight were found after alimentation with either glucose $(P<0.001)$ or $\alpha$-methyl glucoside 
(P $<0.01>0.005)$ compared with the fasted control. No significant increase was observed after feeding isotonic galactose or saccharin alone during the three day fast. Far less galactose and $\alpha$-methyl glucoside was drunk by the rats compared with glucose despite the presence of saccharin in the solutions of the former two sugars (Table 1).

EFFECTS OF FEEDING SUGARS AND SACCHARIN ON KINETIC PARAMETERS OF ACTIVE SUGAR ABSORPTION IN FASTING RATS

Feeding saccharin Saccharin added to the drinking water for three days did not significantly change

\begin{tabular}{|c|c|c|}
\hline & $\begin{array}{l}\text { Jejunal dry wt } \\
(\mathrm{mg} / 10 \mathrm{~cm})\end{array}$ & $\begin{array}{l}\text { Amount sugar } \\
\text { drunk (mmol) }\end{array}$ \\
\hline $\begin{array}{l}\text { Fed controls } \\
\text { Fasted (3 d) }\end{array}$ & $\begin{aligned} 146.7 & \pm 3 \cdot 2(23)^{\mathrm{a}} \\
98 \cdot 7 & \pm 2 \cdot 2(23)\end{aligned}$ & - \\
\hline $\begin{array}{l}\text { Fasted + saccharin } \\
(17 \cdot 3 \mathrm{mg} / 100 \mathrm{ml})\end{array}$ & $100 \cdot 3 \pm 3 \cdot 0(11)$ & - \\
\hline Fasted $+5.4 \%$ glucose & $\begin{array}{l}120 \cdot 4 \pm 3 \cdot 7(18)^{\mathrm{a}} \\
{[+22 \%]}\end{array}$ & $136 \pm 14 \cdot 5(18)$ \\
\hline $\begin{array}{l}\text { Fasted }+5.4 \% \\
\text { galactose }+ \text { saccharin } \\
(17.3 \mathrm{mg} / 100 \mathrm{ml})\end{array}$ & $\begin{array}{l}109 \cdot 7 \pm 3 \cdot 3(20) \\
{[+9 \cdot 3 \%]}\end{array}$ & $46 \pm 6 \cdot 7(20)$ \\
\hline $\begin{array}{l}\text { Fasted }+5.8 \% \\
a \text {-methyl glucoside }+ \\
\text { saccharin }(17.3 \mathrm{mg} / 100 \mathrm{ml})\end{array}$ & $\begin{array}{l}117 \cdot 0 \pm 3 \cdot 8(13)^{b} \\
{[+16 \cdot 7 \%]}\end{array}$ & $68 \pm 7 \cdot 2(13)$ \\
\hline
\end{tabular}

Table 1 Jejunal dry weights in fed rats, fasted rats for three days, rats fasted for three days but allowed ad libitum access to saccharin, and rats allowed free access to various isotonic sugars in their drinking water during three day fast

The total amounts of sugar drunk during the access time are shown in mmol. The results are given as mean $\pm \mathrm{SE}$ of the mean with number of animals used in parentheses. Values in square brackets give the percentage change in dry weight compared with the respective fasted control; ' $a$ ' indicates a very highly significant increase $(P<$ 0.001 ) compared with fasted value, while ' $b$ ' indicates a highly significant increase $(P<0.01)$ compared with the fasted + saccharin value.

\begin{tabular}{|c|c|c|c|}
\hline & \multicolumn{3}{|c|}{ Apparent $K_{m}(m M)$} \\
\hline & Glucose & Galactose & $\begin{array}{l}\text { a-methyl } \\
\text { glucoside }\end{array}$ \\
\hline $\begin{array}{l}\text { Fed controls } \\
\text { Fasted ( } 3 \text { day) } \\
\text { Fasted + saccharin } \\
\text { Fasted }+5.4 \%\end{array}$ & $\begin{array}{l}22.6 \pm 1 \cdot 3(9) \\
10 \cdot 2 \pm 0.4(12) \\
10.2 \pm 0.9(4)\end{array}$ & $\begin{array}{l}32 \cdot 4 \pm 2 \cdot 3(7) \\
16 \cdot 6 \pm 1 \cdot 1(10) \\
16 \cdot 1 \pm 2 \cdot 3(5)\end{array}$ & $\begin{array}{c}31 \cdot 2 \pm 1 \cdot 8(7) \\
11.5 \pm 0.8(6) \\
12.5 \pm 0.9(4)\end{array}$ \\
\hline $\begin{array}{l}\text { glucose } \\
\text { Fasted }+5.4 \% \\
\text { galactose }+\end{array}$ & $22 \cdot 7 \pm 1 \cdot 8(11)$ & $20 \cdot 2 \pm 0 \cdot 8(7)$ & $24 \cdot 3 \pm 1 \cdot 6(6)$ \\
\hline $\begin{array}{l}\text { saccharin } \\
\text { Fasted }+5 \cdot 8 \% \\
a \text {-methyl glucoside } \\
+ \text { saccharin }\end{array}$ & $\begin{array}{l}21.9 \pm 1.2(7) \\
e \\
14.7 \pm 1.3(6)\end{array}$ & $35 \cdot 6 \pm 2 \cdot 6(10)$ & $\begin{array}{r}11.8 \pm 1.8(6) \\
9.4 \pm 0.9(7)\end{array}$ \\
\hline
\end{tabular}

Table 2 'Apparent $K_{m}$ 's' $(m M)$ determined chemically (after correction for diffusion component of absorption) for active absorption of glucose, galactose, and $\alpha$-methyl glucoside in various dietary conditions

Values are given as mean $\pm \mathrm{SE}$ of mean with the number of animals used in parentheses. either the 'apparent $K_{m}$ ' or $V_{\max }$ for glucose, galactose, and $\alpha$-methyl glucoside absorption compared to the fasted animals (Table 2 and 3).

Feeding glucose Feeding glucose during the three day fast maintained the 'apparent $\mathrm{K}_{\mathrm{m}}$ ' for glucose at the fed level but that for galactose was not maintained. With $\alpha$-methyl glucoside, the $K_{m}$ was only partially maintained: it was greater than that of the fasted but was less than that of the fed animals. In the case of $V_{\max }$ 's, glucose feeding maintained that for glucose and $\alpha$-methyl glucoside at the fed level but not that for galactose (Table 3).

Feeding galactose With this sugar, the 'apparent $K_{m}$ 's' for both glucose and galactose were maintained at the fed level but that for $\alpha$-methyl glucoside was not significantly different from the fasted control. While galactose feeding maintained the $V_{\max }$ for glucose at the fed level, it did not influence that for $\alpha$-methyl glucoside nor, surprisingly, that for galactose itself.

Feeding $\alpha$-methyl glucoside There was no effect of $\alpha$-methyl glucoside feeding on the 'apparent $\mathbf{K}_{\mathbf{m}}$ 's' for either galactose or $\alpha$-methyl glucoside absorption. In the case of glucose, however, $\alpha$-methyl glucoside did cause a partial maintenance of the $K_{m}$, the value $(14.7 \pm 1.3 \mathrm{mM})$ was significantly greater than that of the fasted intestine $(10.2 \pm 0.9 \mathrm{mM})$ but less than that in the fed control $(22.6 \pm 1.3 \mathrm{mM})$.

The $V_{\max }$ 's for glucose, galactose, and $\alpha$-methyl glucoside were singularly unaffected by feeding the glucoside, all remained at the level of the fasted controls.

\begin{tabular}{|c|c|c|c|}
\hline & \multicolumn{3}{|c|}{$V_{\max }(\mu \mathrm{mol} / 10 \mathrm{~cm} / 15 \mathrm{~min})$} \\
\hline & Glucose & Galactose & $\begin{array}{l}\text { a-methyl } \\
\text { glucoside }\end{array}$ \\
\hline $\begin{array}{l}\text { Fed controls } \\
\text { Fasted ( } 3 \text { days) } \\
\text { Fasted }+\end{array}$ & $\begin{array}{l}85 \cdot 8 \pm 4 \cdot 1(9) \\
42 \cdot 3 \pm 3 \cdot 5(12)\end{array}$ & $\begin{array}{r}113.0 \pm 11 \cdot 0(7) \\
68.8 \pm 3.4(10)\end{array}$ & $\begin{array}{l}48 \cdot 8 \pm 3.9(7) \\
27.0 \pm 3.0(6)\end{array}$ \\
\hline $\begin{array}{c}\text { saccharin } \\
\text { Fasted }+5.4 \%\end{array}$ & $38 \cdot 5 \pm 4 \cdot 5(4)$ & $65.4 \pm 6.0(5)$ & $29 \cdot 0 \pm 4 \cdot 4(4)$ \\
\hline $\begin{array}{l}\text { glucose } \\
\text { Fasted }+5.4 \% \\
\text { galactose }+\end{array}$ & $72 \cdot 8 \pm 7 \cdot 7(11)$ & $62 \cdot 5 \pm 5 \cdot 8(7)$ & $42 \cdot 2 \pm 4 \cdot 1(6)$ \\
\hline $\begin{array}{l}\text { saccharin } \\
\text { Fasted }+5.8 \% \\
a \text {-methyl gluco }\end{array}$ & $\begin{array}{l}78 \cdot 3 \pm 5 \cdot 5(7) \\
\text { ide }\end{array}$ & - & $27 \cdot 4 \pm$ \\
\hline + saccharin & $51 \cdot 4 \pm 4.8(6)$ & $50.1 \pm 6.9(7)$ & $22.0 \pm 0.8(7)$ \\
\hline
\end{tabular}

Table $3 V_{\max }$ for active absorption of glucose, galactose, and $\alpha$-methyl glucoside in various dietary conditions

The values have been corrected for the diffusive component of transfer (see text), and are given as the mean $\pm S E$ of the mean with number of animals used in parentheses. The $V_{m a x} s$ for fed and fasted animals have been published previously (Debnam and Levin, $1975 \mathrm{a}, \mathrm{b}$ ). 
TIME COURSE OF CHANGES IN 'APPARENT $\mathrm{K}_{\mathrm{m}}$ ' ON FEEDING SUGARS TO FASTING RATS In order to assess how quickly a feeding sugar restored the 'apparent $\mathrm{K}_{\mathrm{m}}$ ' of sugar transport mechanisms in the intestine of fasted rats to the fed level, two experiments were conducted. Rats were fasted for the usual three days but were allowed ad libitum access to the feeding sugar (in the drinking water) for specific, limited access times of $4,12,18$, 24 , or $72 \mathrm{~h}$. In the first experiment, the influence of glucose (metabolized by the intestine) was assessed on the 'apparent $\mathrm{K}_{\mathrm{m}}$ ' for electrogenic glucose transfer (Fig. 1). In the second experiment, the sugar $\alpha$-methyl glucoside (not metabolized by the intestine) was fed and its influence on the $K_{m}$ for electrogenic galactose transfer was assessed (Fig. 2). In both experiments the 'apparent $K_{m}$ ' were obtained from the transfer pds (Debnam and Levin, 1975a). Feeding the isotonic glucose caused a significant increase in the $\mathrm{K}_{\mathrm{m}}$ for glucose between the final 12 and $24 \mathrm{~h}$. Similar results were obtained with $\alpha$-methyl glucoside feeding, the glucoside influenced the 'apparent $\mathrm{K}_{\mathrm{m}}$ ' for galactose transport when present in the lumen for the final 18-24 $\mathrm{h}$ of the three day fast (Fig. 2).

\section{Discussion}

It has been established that fasting rats for three days causes large decreases in both the 'apparent $\mathrm{K}_{\mathrm{m}}$ ' and the $\mathrm{V}_{\max }$ of the active sugar transfer mechanisms of the jejunum when measured in vivo (Debnam and Levin, 1973; 1975b). The experimental evidence that these kinetic changes are specific and not caused by alterations in unstirred layers or nonspecific factors has already been presented and will not be discussed further (Debnam and Levin, 1975b). In the present study, feeding glucose, galactose or $\alpha$-methyl glucoside to fasting rats for up to three days caused highly significant changes in the 'apparent $\mathrm{K}_{\mathrm{m}}$ ' and the $\mathrm{V}_{\max }$ of the active transfer mechanisms for these sugars. The effects (Tables $2,3)$ are summarized for convenience in Table 4, which is constructed to reveal whether the dietary sugars did or did not maintain the $\mathrm{K}_{\mathrm{m}}$ and $\mathrm{V}_{\max }$ of each specific transport mechanism at the level of

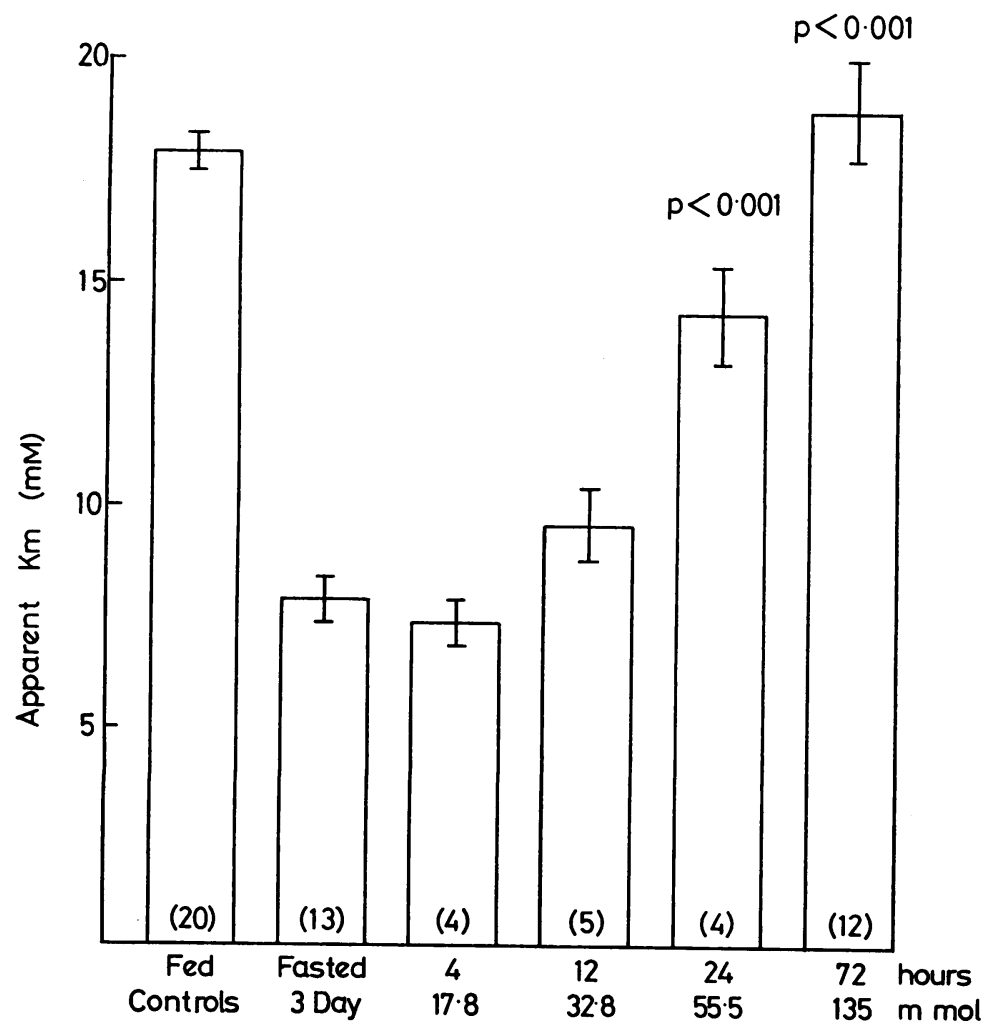

Fig. 1 The time course of the changes induced in the 'apparent $K_{m}$ ' for electrogenic glucose absorption in vivo brought about by feeding isotonic glucose in the drinking water to rats fasted for three days. The time that the rats had access to the isotonic sugar and the cumulative amount consumed is calculated from the time the animal was used for assessing absorption-that is, $4 \mathrm{~h}$ indicates that the animal was fasted for $68 \mathrm{~h}$ and in the last $4 \mathrm{~h}$ had access to glucose and drank $17.8 \mathrm{mmol}$. The results are expressed as the mean $\pm S E$ of the mean. The number in parentheses at the base of the bars represents the number of animals used. The levels of significance are for the comparison of the 'apparent $K_{m}$ 's' to the fasted (three day) value. All the $K_{m}$ 's were obtained by the electrical technique (see methods). 


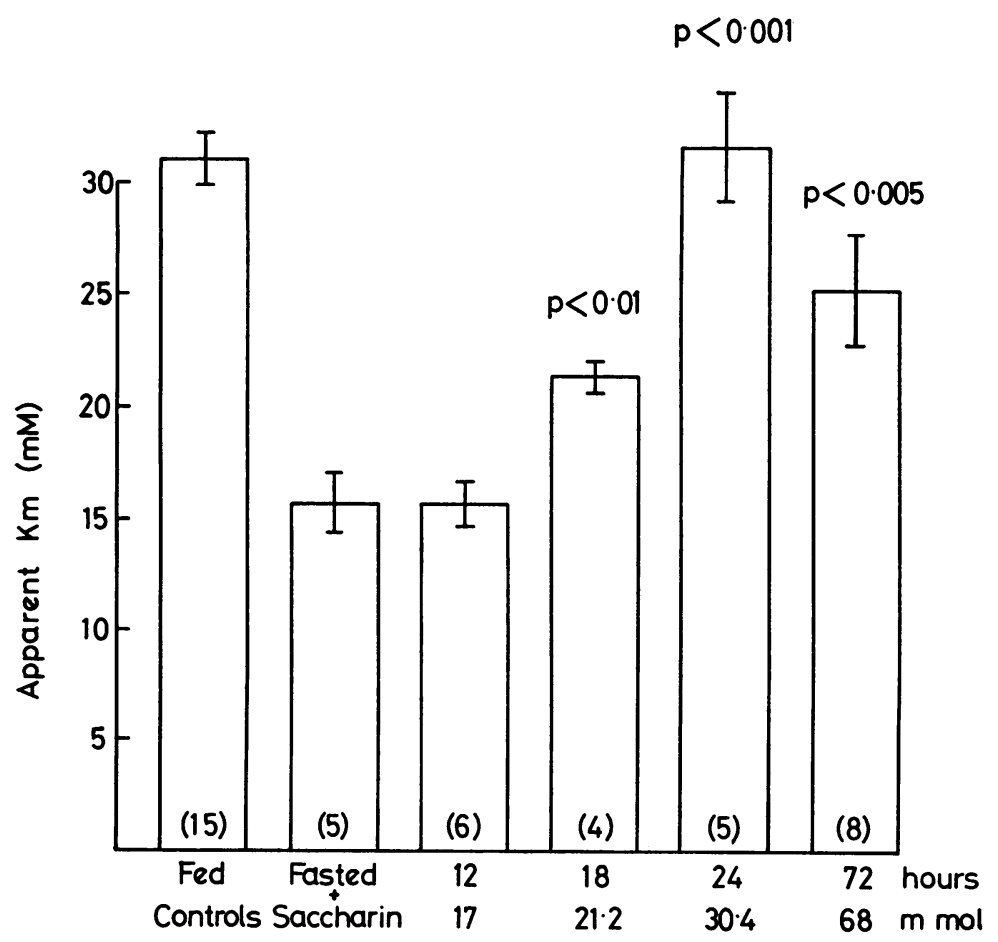

Fig. 2 The time course of the changes in the 'apparent $K_{m}$ ' for electrogenic galactose absorption in vivo brought about by the feeding of isotonic $\alpha$-methyl glucoside in the drinking water to rats fasted for three days. The access times, amounts of the sugar consumed, and the levels of significance are explained in the legend to Fig. 1. fed controls. Examination of the table clearly shows that the feeding sugars induce complex changes in the kinetic parameters. Despite the complexity, a number of conclusions can be drawn. In the case of the 'apparent $K_{m}$ 's', it is clear that a dietary sugar does not automatically maintain the $K_{m}$ for its own transport system; while glucose and galactose maintained their own $\mathbf{K}_{\mathbf{m}}$ 's, $\alpha$-methyl glucoside feeding did not influence its $\mathrm{K}_{\mathrm{m}}$. It appears immaterial whether a feeding sugar is metabolized by the intestine as to its actions on transport mechanisms. Glucose, although well-metabolized by the enterocytes, was not able to maintain the 'apparent $\mathbf{K}_{\mathbf{m}}$ 's' for galactose and only partially maintained that for $\alpha$-methyl glucoside. In contrast, the feeding of galactose, a hexose very poorly metabolized by rat enterocytes, maintained the $\mathbf{K}_{\mathbf{m}}$ 's for glucose and galactose but not that for $\alpha$-methyl glucoside. The influence of dietary sugars on the $V_{\max }$ for the test sugars varied considerably. Feeding either glucose or galactose maintained the $\mathrm{V}_{\max }$ for glucose at the fed level but $\alpha$-methyl glucoside did not increase the $V_{\max }$ for glucose significantly above the level of the fasted group. Surprisingly, in the case

\begin{tabular}{|c|c|c|c|c|c|c|}
\hline \multirow[t]{2}{*}{ Test sugar } & \multicolumn{3}{|l|}{ 'Apparent $K_{m}$ ' } & \multicolumn{3}{|l|}{$V_{\max }$} \\
\hline & $\begin{array}{l}\text { Fasted } \\
+ \\
\text { glucose } \\
\text { feeding } \\
\text { (a) }\end{array}$ & $\begin{array}{l}\text { Fasted } \\
+ \\
\text { galactose } \\
\text { feeding } \\
\text { (b) }\end{array}$ & $\begin{array}{l}\text { Fasted } \\
+ \\
\text { a-methyl glucoside } \\
\text { feeding } \\
\text { (c) }\end{array}$ & $\begin{array}{l}\text { Fasted } \\
+ \\
\text { glucose } \\
\text { feeding } \\
\text { (d) }\end{array}$ & $\begin{array}{l}\text { Fasted } \\
+ \\
\text { galactose } \\
\text { feeding } \\
(e)\end{array}$ & $\begin{array}{l}\text { Fasted } \\
+ \\
\alpha-\text {-methyl glucoside } \\
\text { feeding } \\
\text { (f) }\end{array}$ \\
\hline $\begin{array}{l}\text { Glucose } \\
\text { Galactose } \\
\alpha \text {-methyl glucoside }\end{array}$ & $\begin{array}{l}\text { Maintained } \\
\text { Not maintained } \\
\text { Partially maintained }\end{array}$ & $\begin{array}{l}\text { Maintained } \\
\text { Maintained } \\
\text { Not maintained }\end{array}$ & $\begin{array}{l}\text { Partially maintained } \\
\text { Not maintained } \\
\text { Not maintained }\end{array}$ & $\begin{array}{l}\text { Maintained } \\
\text { Not maintained } \\
\text { Maintained }\end{array}$ & $\begin{array}{l}\text { Maintained } \\
\text { Not maintained } \\
\text { Not maintained }\end{array}$ & $\begin{array}{l}\text { Not maintained } \\
\text { Not maintained } \\
\text { Not maintained }\end{array}$ \\
\hline
\end{tabular}

Table 4 Effects of feeding sugars on 'apparent $K_{m}$ ' and $V_{\max }$ of sugar absorption mechanisms, a summary of data in Tables 2 and 3

The 'apparent $\mathrm{K}_{\mathrm{m}}$ ' and $\mathrm{V}_{\max }$ are compared with those observed in the fed controls: if the feeding sugar kept either parameter at the fed level the word 'maintained' is inserted, if the feeding sugar had no effect the words 'not maintained' are used, and where the feeding sugar caused a parameter to be significantly different from both the fasted and the fed condition the words 'partially maintained' are used. 
of galactose, none of the feeding sugars was able to maintain its $V_{\max }$ at the fed level. With $\alpha$-methyl glucoside, only glucose maintained its $V_{\max }$, the other two sugars were ineffective. The changes in $V_{\max }$ induced by the feeding sugars cannot be explained simply by alterations of the various structural components of the intestine, for the differential changes in parameters observed in each of the vertical columns (marked d, e, and f, Table 4) are obtained in intestines exposed to identical dietary conditions-that is, all those that were fed glucose would lose or gain structural components in an identical manner; this would also apply to those fed galactose or $\alpha$-methyl glucoside. Yet in the vertical groups for glucose and galactose feeding ( $a$ and $b$, Table 4) the $V_{\max }$ 's for the test sugars behave differently. This must indicate that the changes occur in the enterocytes rather than in their numbers or in structural alterations in the gut.

The maintenance of the 'apparent $\mathrm{K}_{\mathrm{m}}$ ' for a particular transport mechanism does not predict that its $V_{\max }$ will also be maintained-for example, when galactose was fed, the 'apparent $\mathrm{K}_{\mathrm{m}}$ ' for galactose absorption was maintained at the level of the fed control but its $V_{\max }$ remained at the fasted level. Cleland (1967) has argued that when the $K_{m}$ 's and $V_{\max }$ 's for a mechanism exposed to changed conditions are compared, if they alter in different directions this constitutes the strongest evidence for accepting that a real change in the kinetic parameters for the mechanism has taken place. Thus the differential changes in the 'apparent $\mathrm{K}_{\mathrm{m}}$ ' and $\mathrm{V}_{\max }$ for galactose transfer presents the first experimental evidence that feeding galactose to fasted animals induces changes in the 'carrier mechanisms' for this sugar.

TIME COURSE OF CHANGES IN 'APPARENT $\mathrm{K}_{\mathrm{m}}$ ' DURING FEEDING SUGARS TO FASTING ANIMALS

Feeding either a metabolized (glucose) or nonmetabolized sugar ( $\alpha$-methyl glucoside) to fasting rats altered the 'apparent $\mathrm{K}_{\mathrm{m}}$ ' for glucose and galactose absorption respectively within $12-24 \mathrm{~h}$. Thus the changes in the transport mechanism can be measured experimentally (in the case of glucose) as early as $12 \mathrm{~h}$ after feeding the sugar. This time course has a significant bearing on the type of mechanism offered to explain the changes.

POSSIBLE MECHANISMS BY WHICH DIETARY SUGARS CREATE ALTERATIONS IN INTESTINAL SUGAR TRANSPORT

Roy and Dubois (1972) measured the active transfer of the non-metabolized glucalogue 3-0-methyl glucose at a single concentration across jejuna removed from fasted animals and those fed glucose, fructose, or 3-0-methyl glucose. Despite the absence of any kinetic analysis of absorption or any morphological assessment, they proposed that the specific mechanism for the entry and transport of the glucalogue 'was adaptive only to a metabolizable monosaccharide ... in a non-specific fashion', since glucose and fructose were equally effective in increasing its transport compared with the fasted gut. The adaptive changes did not correlate with those of the particle-free hexokinase (EC2.7.1.1) activity of the mucosa. More recently Menge et al. (1975) reported that infusions of glucose or galactose into self-emptying blind loops of jejunum enhanced their absorption, in vivo, of glucose. Unfortunately, the assessment of absorption was also made at a single concentration, thus precluding any critical assessment of the actions of the sugars on the active transport mechanisms for glucose. Our extensive kinetic data obtained with three actively transported sugars (one metabolized and two non-metabolized by the enterocytes) has revealed that the situation is much more complex than could be inferred from the absorption studies of Roy and Dubois or Menge et al. They show furthermore that it is essential to study the absorption processes by a kinetic approach in order to evaluate effects on 'carrier affinity' (apparent $\mathbf{K}_{\mathrm{m}}$ 's) and maximum transfer otherwise serious interpretative errors can occur.

We have found that feeding galactose (a sugar not metabolized by the intestine) can cause changes in the transport mechanism for a metabolized one (maintains $\mathrm{K}_{\mathrm{m}}$ for glucose) and that feeding a metabolized sugar (glucose) can either have no influence on the mechanisms for a non-metabolized sugar (the $\mathrm{V}_{\max }$ for galactose absorption is unchanged by glucose feeding) or can positively effect a mechanism for a non-metabolized sugar (glucose feeding maintaining the $\mathrm{V}_{\max }$ for $\alpha$-methyl glucoside). These complex interactions give rise to the evidence for thinking that more than one transport mechanism must exist in the jejunal enterocytes for the various sugars. Further discussion on this topic will be in a later section.

A number of studies have reported that feeding sugars to fasted rats induces increases in the hexokinase activity of enterocytes within a few minutes of contact with the intestine (Mayer et al., 1970; Jones and Mayer, 1973; Van der Berg and Hülsman, 1971). This sugar-dependent increase in hexokinase activity was claimed by Mayer et al. (1970) to be important in regulating metabolism as a source of energy for active transport processes in the enterocyte. Other workers have also stressed the critical importance of hexokinase and its cellular compartmentalization (Srivastava and Hübscher, 1966; 
Anderson et al., 1971; Anderson and Tyrrell, 1973). Are the changes in $V_{\max }$ that we observe after feeding various sugars due to changes in the activity or disposition of hexokinase in the enterocytes? There are two reasons that make this hypothesis unlikely. Firstly, although all the feeding sugars are actively transferred by the intestine, they did not all restore the $V_{\max }$ 's of all the transport systems (Table 4). Second, our method of measuring absorption ensures that all the sugars have to be in contact with the intestine for $\mathbf{7 5}$ minutes (five periods of 15 minutes). According to Mayer et al. (1970) this contact time should have created significant changes in hexokinase activity and thus influence the $V_{\max }$ for the sugar. Because some $V_{\max }$ 's were not restored, alterations in the enzyme distribution can have little influence on our results.

In the case of the 'apparent $\mathrm{K}_{\mathrm{m}}$ 's', the changes induced by feeding sugars to fasted rats take much longer to be manifest (that is, 12-24 h) than those reported for changes in hexokinase activity ( $5 \mathrm{~min}$ ). Clearly, mechanisms other than alterations in hexokinase distribution are operating to change $\mathrm{K}_{\mathrm{m}}$ 's. At the present, we can only speculate about the cellular mechanisms by which dietary sugars induce the changes in $V_{\max }$ and $\mathrm{K}_{\mathrm{m}}$. If the changes in $K_{m}$ are indicative of the changes of the affinity of the sugar carrier then they could arise in three ways: (1) by the carrier being directly modified by the absence or presence of the feeding sugar; (2) by the feeding sugar activating the formation of a new generation of enterocytes from the crypts with the appropriate new carriers; (3) by the feeding sugar changing the ratio of carriers already present in the brush-border membrane.

While it is not possible at the present to distinguish experimentally between the suggestions, they raise the question of whether the enterocytes possess more than one carrier for active sugar transfer.

MULTIPLE CARRIERS FOR SUGAR TRANSFER The results obtained in this study, together with those obtained in the fasting animal published previously (Debnam and Levin, 1971; Debnam and Levin, 1975b), can be interpreted as strong evidence that more than one mechanism for the transfer of sugars across the rat jejunum exists in vivo. The differential changes of 'apparent $\mathrm{K}_{\mathrm{m}}$ ' and of $\mathrm{V}_{\max }$ for the test sugars after feeding glucose, galactose, and $\alpha$-methyl glucoside to fasted animals are clearly incompatible with the concept of a common, single transport mechanism (carrier?) for all actively transported sugars proposed by Wilson (1962). Apart from the present studies, there is now a growing body of direct and indirect evidence indicating that sugar transfer is mediated by more than one transport system both in vitro (Newey et al., 1966; Levin and Syme, 1971; Honegger and Semenza, 1971; Malathi et al., 1973; Honegger and Gershon, 1974) and in vivo (man: Meeuwisse and Melin, 1969; rat: McMichael, 1971; 1973; 1975). The role of these multiple transport systems in intestinal absorption cannot yet be defined. Carrier systems have always shown many similarities to enzyme properties and it may well be that the multiple forms of carriers are analogous to isozymes (multiple forms of enzymes with highly similar qualitative but different quantitative activities). The multiple forms of the sugar carriers (isocarriers?) may be involved in the facultative responses of the enterocytes to changes in the dietary levels of sugar (see Levin (1976) for further discussion).

It is worthwhile concluding with some practical difficulties that hexose 'isocarriers' may create in the evaluation of absorption mechanisms in clinical and experimental studies. There is clearly a danger in using only one actively transferred hexose to evaluate developmental, dietary or disease-induced changes in active transfer mechanisms for the dietary sugars (glucose and galactose). This is especially so if the sugar chosen is an artificial, non-metabolized, non-dietary substrate and the studies are carried out in vitro (Genel et al., 1971; Beck et al., 1973). The conclusions from such data need verification from kinetic studies undertaken in vivo with the normal dietary sugars.

E.S.D. is indebted to the Medical Research Council for a scholarship during the tenure of which this work was carried out.

\section{References}

Anderson, J. W., Herman, R. H., Tyrrell, J. B., and Cohn, R. M. (1971). Hexokinase: a compartmented enzyme. American Journal of Clinical Nutrition, 24, 642-650.

Anderson, J. W., and Tyrrell, J. B. (1973). Hexokinase activity of rat intestinal mucosa: demonstration of four isozymes and of changes in subcellular distribution with fasting and refeeding. Gastroenterology, 65, 69-76.

Beck, I. T., Dinda, P. K., Da Costa, L. P., and Beck, M. (1973). 3-0-Methyl-D-glucose uptake by small bowel biopsies from patients with adult celiac disease. Gastroenterology, 64, 877.

Cleland, W. W. (1967). The statistical analysis of enzyme kinetic data. Advances in Enzymology, 29, 1-32.

Crouzoulon-Bourcat, C., Crouzoulon, G., and Pérès, G. (1971). Recherches sur l'absorbtion intestinale des hexoses. II. Effets de quelques régimes simples sur l'absorption intestinale du fructose in vivo. Compte Rendu des Seances de la Société de Biologie et de ses Filiales, 165, 1071-1074.

Debnam, E. S., and Levin, R. J. (1971). Evidence for separate hexose carriers in the small intestine uncovered by fasting and glucose alimentation. Journal of Physiology, 218, 38P-39P.

Debnam, E. S., and Levin, R. J. (1973). Assessment of the effects of starvation and semi-starvation on the opera- 
tional kinetic parameters of the active transfer of hexoses measured in vivo. Journal of Physiology, 231, 21 P-23P.

Debnam, E. S., and Levin, R. J. (1974). Dietary sugars and the maximum absorptive capacity of the small intestine; further evidence for multiple hexose transfer mechanisms. Journal of Physiology, 238, 81P-82P.

Debnam, E. S., and Levin, R. J. (1975a). An experimental method of identifying and quantifying the active transfer electrogenic component from the diffusive component during sugar absorption measured in vivo. Journal of Physiology, 246, 181-196.

Debnam, E. S., and Levin, R. J. (1975b). Effects of fasting and semi-starvation on the kinetics of active and passive sugar absorption across the small intestine in vivo. Journal of Physiology, 252, 681-700.

Donhoffer, Sz. (1935). Über die elektive Resorption der Zucker. Archiv für experimentelle Pathologie und Pharmakologie, 177, 689-692.

Genel, M., London, D., Holtzapple, P. G., and Segal, S. (1971). Uptake of alpha-methylglucoside by normal and diabetic human jejunal mucosa. Journal of Laboratory and Clinical Medicine, 77, 743-750.

Honegger, P., and Gershon, E. (1974). Further evidence for the multiplicity of carriers for free glucalogues in hamster small intestine. Biochimica et Biophysica Acta, 352, 127-134.

Honegger, P., and Semenza, G. (1973). Multiplicity of carriers for free glucalogues in hamster small intestine. Biochimica et Biophysica Acta, 318, 390-410.

Jones, G. M., and Mayer, R. J. (1973). Glucose metabolism in the rat small intestine: the effect of glucose analogues on hexokinase activity. Biochemical Journal, 132, 125-128.

Krebs, H. A., and Henseleit, K. (1932). Untersuchungen uber die Harnstoff bildung im Tierkörper. Hoppe-Seyler's Zeitschrift für physiologie und Chemie, 210, 33-66.

Levin, R. J. (1976). Digestion and absorption of carbohydrate-from embryo to adult. In Digestion in the Fowl, edited by K. N. Boorman and B. M. Freeman. British Poultry Science Ltd: Edinburgh.

Levin, R. J., and Syme, G. (1971). Differential changes in the 'apparent $K_{m}$ ' and maximum potential difference of the hexose and amino acid electrogenic transfer mechanisms of the small intestine, induced by fasting and hypothyroidism. Journal of Physiology, 213, 46P-48P.
Lineweaver, H., and Burk, D. (1934). The determination of enzyme dissociation constants. Journal of the American Chemical Society, 56, 658-666.

McMichael, H. B. (1971). Intestinal absorption of carbohydrates in man. Proceedings of the Nutrition Society, 30 , 248-254.

McMichael, H. B. (1973). A second intestinal glucose carrier. Gut, 14, 428-429. (Abstract).

McMichael, H. B. (1975). Clinical studies of carbohydrate digestion and absorption. Biochemical Society Transactions, 3, 223-227. (Abstract).

Malathi, P. M., Ramaswamy, K., Caspary, W. F., and Crane, R. K. (1973). Studies on the transport of glucose from disaccharides by hamster small intestine in vitro. I. Evidence for a disaccharidase-related transport system. Biochimica et Biophysica Acta, 307, 613-626.

Mayer, R. J., Shakespeare, P., and Hübscher, G. (1970) Glucose metabolism in mucosa of the small intestine. Biochemical Journal, 116, 43-48.

Menge, H., Werner, H., Lorenz-Meyer, H., and Riecken, E. O. (1975). The nutritive effect of glucose on the structure and function of jejunal self-emptying blind loops in the rat. Gut, 16, 462-467.

Meeuwisse, G. W., and Melin, K. (1969). Studies in glucosegalactose malabsorption. Acta Paediatrica Scandinavica, 58, Suppl. 188, 3-24.

Newey, H., Sanford, P. A., and Smyth, D. H. (1966). The effect of uranyl nitrate on intestinal transfer of hexoses. Journal of Physiology, 186, 493-502.

Roy, C. C., and Dubois, R. S. (1972). Monosaccharide induction of 3-0-methyl glucose transport through the rat jejunum. Proceedings of the Society for Experimental Biology and Medicine, 139, 883-886.

Srivastava, L. M., and Hübscher, G. (1966). Glucose metabolism in the mucosa of the small intestine. Biochemical Journal, 100, 458-466.

Van den Berg, J. W. O., and Hülsmann, W. C. (1971) Insoluble hexokinase in the brush border region of rat intestinal epithelial cells. FEBS Letters, 12, 173-175.

Westenbrink, H. G. K. (1934). Über die Anpassung der Darmresorption an die Zusammensetzung der Nahrung. Archives Néerlandaises de Physiologie de l'Homme et des Animaux., 19, 563-583.

Wilson, T. H. (1962). Intestinal Absorption, p. 91. Saunders: Philadelphia. 